\title{
Identification of signal characteristics in the analysis of free-field vibration caused by trains
}

\author{
Barbara Kożuch ${ }^{1, *}$ and Tadeusz Tatara ${ }^{1}$ \\ ${ }^{1}$ Institute of Structural Mechanics, Cracow University of Technology, Poland
}

\begin{abstract}
The paper deals with a selection of free-field vibration measurement results. The study is based on the vibration measurements. Vibration acceleration records and their dependence on the position of the accelerometer are shown. The study presents the results obtained in time domain and frequency domain (FFT). Nevertheless, the main aim of the paper is to compare the results of analysis which use the time - frequency domain. A Short-Term Fourier Transform (STFT) and Continuous Wavelet Transform (CWT) are used. The use of new methods to assess the dynamic characteristics is to validate the usefulness of proposed technique for nonstationary signals.
\end{abstract}

\section{Introduction}

Trains passages generate ground vibration, and the review of the worldwide literature (e.g. [1-5]) indicates that these vibrations are increasing engineering challenge and become a global concern. The problem is not unknown in the well-developed countries. Therefore, transport plays an important role in shaping the quality of the environment.

For this reason, large scale national testing of railway vibration took place in Poland at the railway line No. 4. For the use of the newly purchased Pendolino trains, homologation tests were conducted. Selected for testing train Pendolino was running at predetermined speeds. Pendolino and InterCity (the train with the locomotive ES64U4 Husarz) excited free-field vibrations. Detailed information about the study can be found at [6].

The paper presents a selection of free-field vibration measurement results in the selected point (in three directions, defined as P-04x for horizontal (perpendicular to the track), P-05y (parallel to the track) and P-06z vertical downward). A PCB Piezotronics piezoelectric transducers and a SCADAS Mobile LMS International analyser were used to perform in situ measurements. Accelerometers were fixed on the ground surface, $2.3 \mathrm{~m}$ below the railhead level, next to the railway embankment. The schematic arrangement of the sensors is shown in Fig. 1. Results of free-field vibrations caused by two types of trains running at the speed of $160 \mathrm{~km} / \mathrm{h}$ were analysed to make comparison that is more tangible.

\footnotetext{
* Corresponding author: kozuchbm@gmail.com
} 


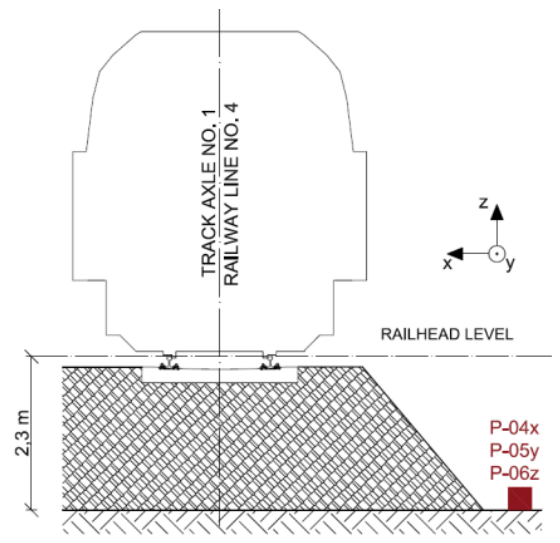

Fig. 1. Measuring polygon - schematic arrangement of sensors.

\section{Experimental analyses}

\subsection{Fast Fourier Transform}

The transition from the time domain (time histories ground surface acceleration) to the frequency domain was performed using Fast Fourier Transform (FFT). Transform was implemented for frequencies of up to $200 \mathrm{~Hz}$. Fig. 2 presents each FFT of the acceleration record at ground surface (the directions $\mathrm{x}, \mathrm{y}, \mathrm{z}$ ), located at $2.3 \mathrm{~m}$ below railhead level for InterCity train. The data for Pendolino are shown in Fig. 3, in analogy. The largest amplitude of the vibrations for InterCity train occurs in the y direction (P-05y) and it is $9.5 \mathrm{~cm} / \mathrm{s}^{2}$ at frequency $68 \mathrm{~Hz}$. The significant frequency band for the horizontal components (P-04x and P-05y) is frequency band of $50-115 \mathrm{~Hz}$. For the vertical component the significant frequency band is narrower and it is in the range of $50-90 \mathrm{~Hz}$. In the horizontal plane, the Pendolino train induces slightly lower parallel vibrations (P-05-y) but higher perpendicular ones $(\mathrm{P}-04 \mathrm{x})$. The dominant frequency band is similar to the previously discussed one.

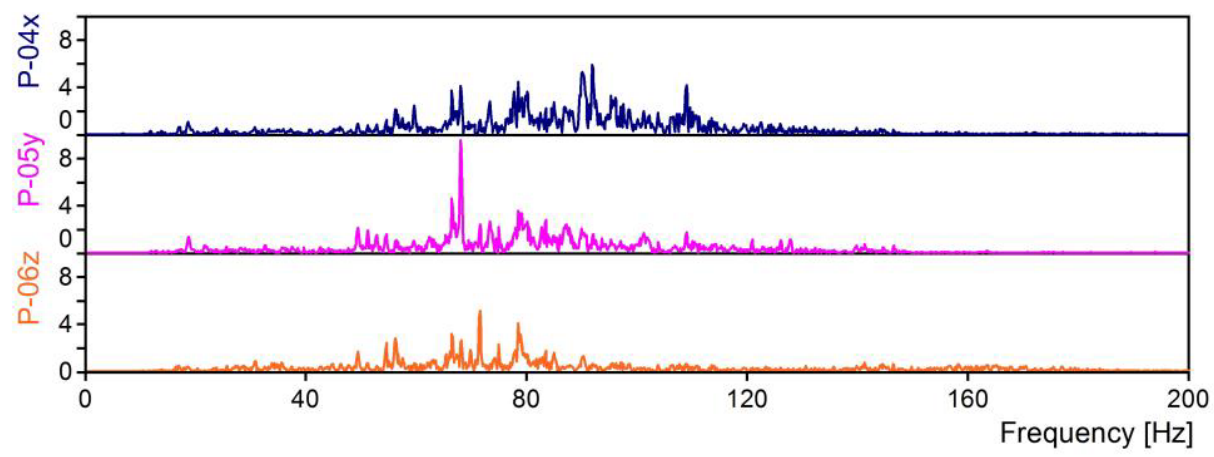

Fig. 2. The value of FFT for InterCity train - sensors P-04x, P-05y, P-06z. 


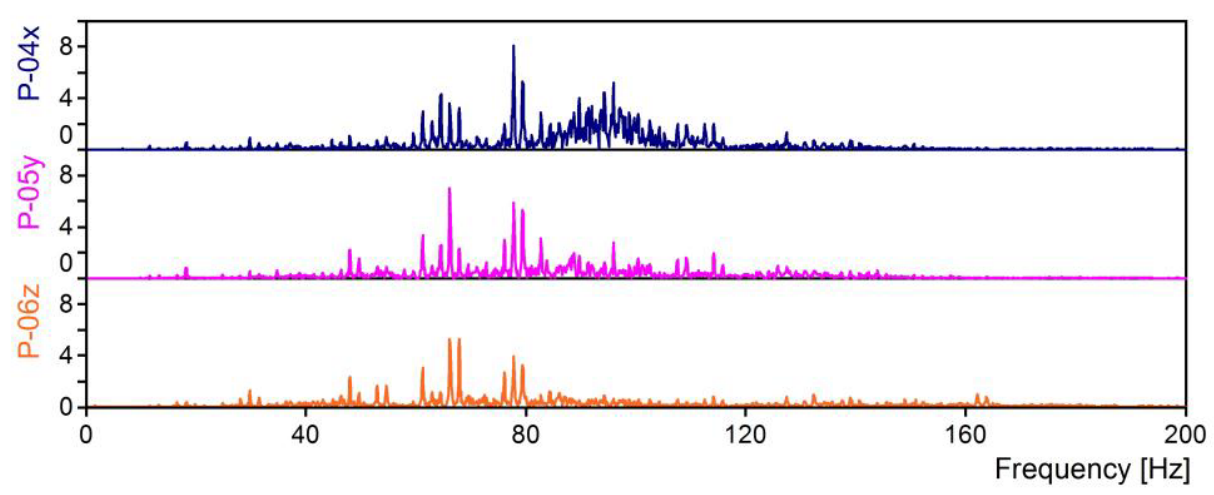

Fig. 3. The value of FFT for Pendolino train - sensors P-04x, P-05y, P-06z.

\subsection{Analysis in time and frequency domain}

FFT plays an important role in vibration analysis. It gives us the messages about the nature of the excited vibration, but the main drawback is that FFT does not include changing in time duration. Proceeding from the time domain to the frequency domain, we lose the information about the exact duration of the event and the beginning of individual excitations of vibrations during the course, which is particularly important in the decline of non-stationary vibration sources. Therefore, in further elaboration of the results it was decided to use the Short-Term Fourier Transform (STFT). The advantages of introduce analyzes which obtain data in the time - frequency domain are shown in reference [7].

The next step in the signal analysis is the Continuous Wavelet Transform (CWT). CWT is relatively new method and it was developed to improve the performance of STFT. The information and proposal to apply this analysis are available in references [8-10].

Signal analysis using STFT and CWT are presented for transducers P-04x, P-05y, P-06z in Figs. 4-6, respectively. It is used a scale - normalized $\mathrm{dB}$ to compare both analysis. The value of the amplitudes $\left[\mathrm{cm} / \mathrm{s}^{2}\right]$ generated by the different runs was obtained from the FFT. In this case, the share of component in time - frequency domain was interesting, and therefore we decided on such a scale. Zero indicates maximum obtained amplitude. Other values are related to the reference value. In each figures the first columns are graphs obtained by applying the CWT analysis.

The first row in Fig. 4 shows the analysis for the Pendolino train. The eight points of excitation is clearly visible during the passage of a train. It has been associated with eight groups of wheels' sets. Schematic arrangement of bogies is shown in Fig. 7. The first and the last group contain half the numbers of wheels, therefore induced vibrations are reduced there. The discussed distribution in time domain is shown better in CWT graph. However, with such selected parameters, distribution in frequency domain is better illustrated in the STFT graph. The bottom row presents graphs for InterCity train. This is a typical arrangement for that train type - locomotive plus carriages. We can observe the largest amplitude for the first element (locomotive), and much less for the rest of the train (carriages). As above, in this case, CWT better represents characteristic of acceleration record in time domain but STFT better refers to frequency domain. 

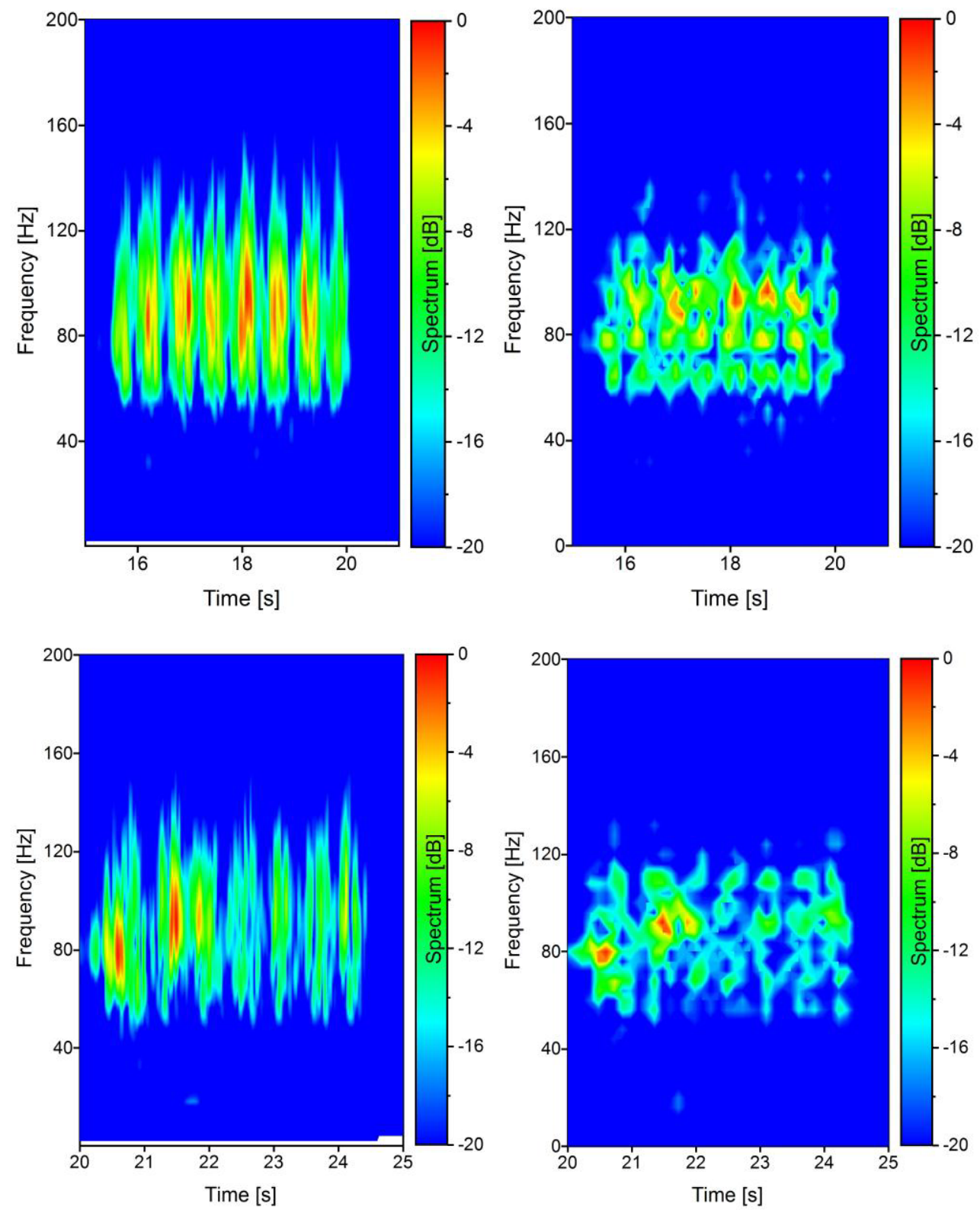

Fig. 4. Sensor P-04x - the value of CWT (the left column) and STFT (the right column) for Pendolino train (the upper row) and the value of CWT (the left column) and STFT (the right column) for InterCity train (the bottom row).

Graphs obtained for horizontal vibrations parallel to the axis of the railway track (P$05 y$ ) are shown in Fig. 5. The analyzes of the vibration records for this point (next to railway embankment) reveal a very similar nature of the two horizontal components of vibrations ( $\mathrm{x}$ and $\mathrm{y}$ ). 

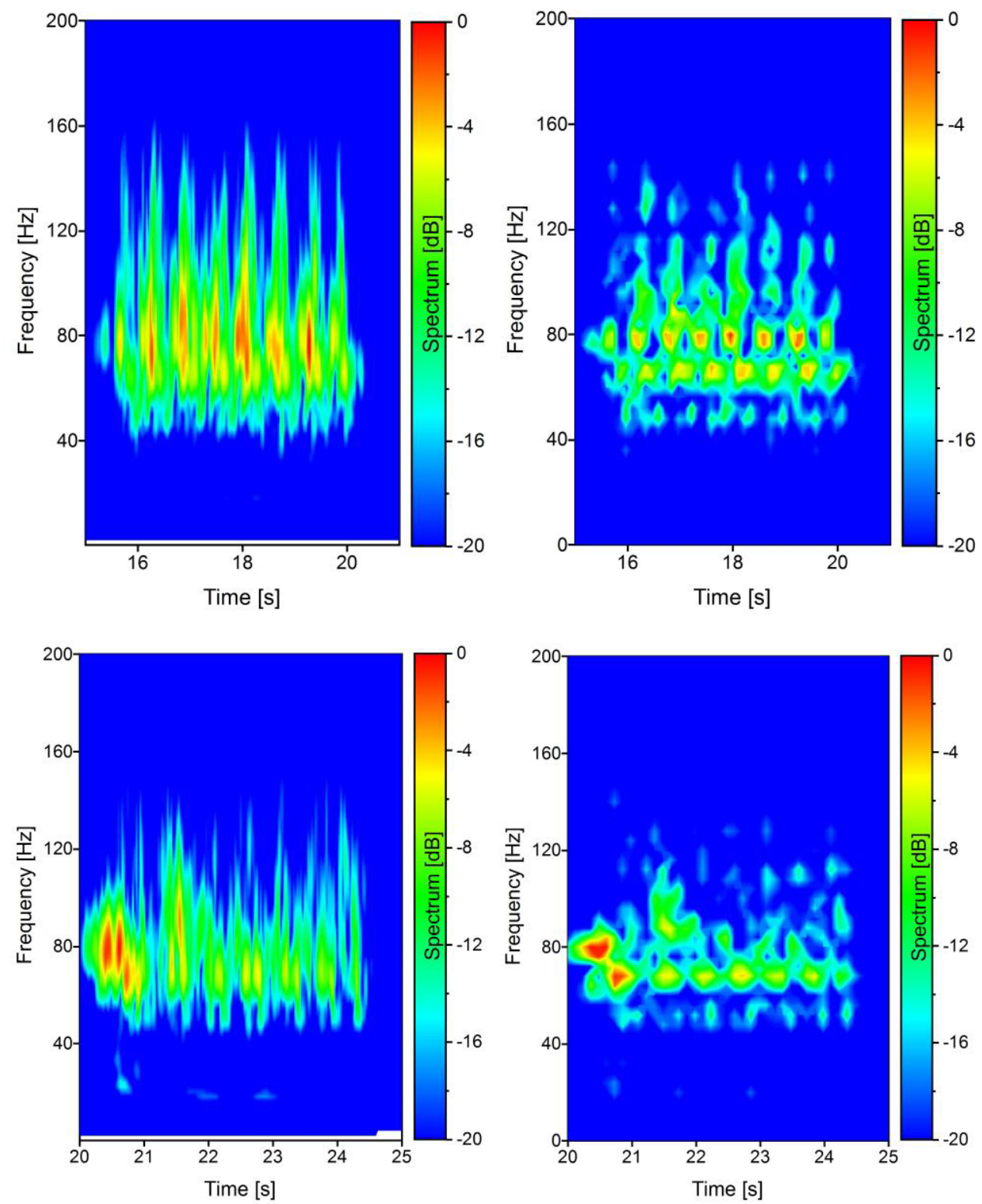

Fig. 5. Sensor P-05y - the value of CWT (the left column) and STFT (the right column) for Pendolino train (the upper row) and the value of CWT (the left column) and STFT (the right column) for InterCity train (the bottom row).

The values for the vertical component of vibration (P-06z) are a bit different. During the passages of Pendolino trains, vibration for the first and last group of wheels is higher in comparison to the other groups than in the previous cases. In the example of the InterCity train, the greatest strength of the signal occurs in the first second of movement. In both events, it can also be seen not negligible bandwidth vibration frequencies of about $160 \mathrm{~Hz}$, which does not exist for horizontal vibration. The same as for horizontal vibration, the representation of the time axis is better introduced by CWT but the frequency axis is more visible in STFT. 

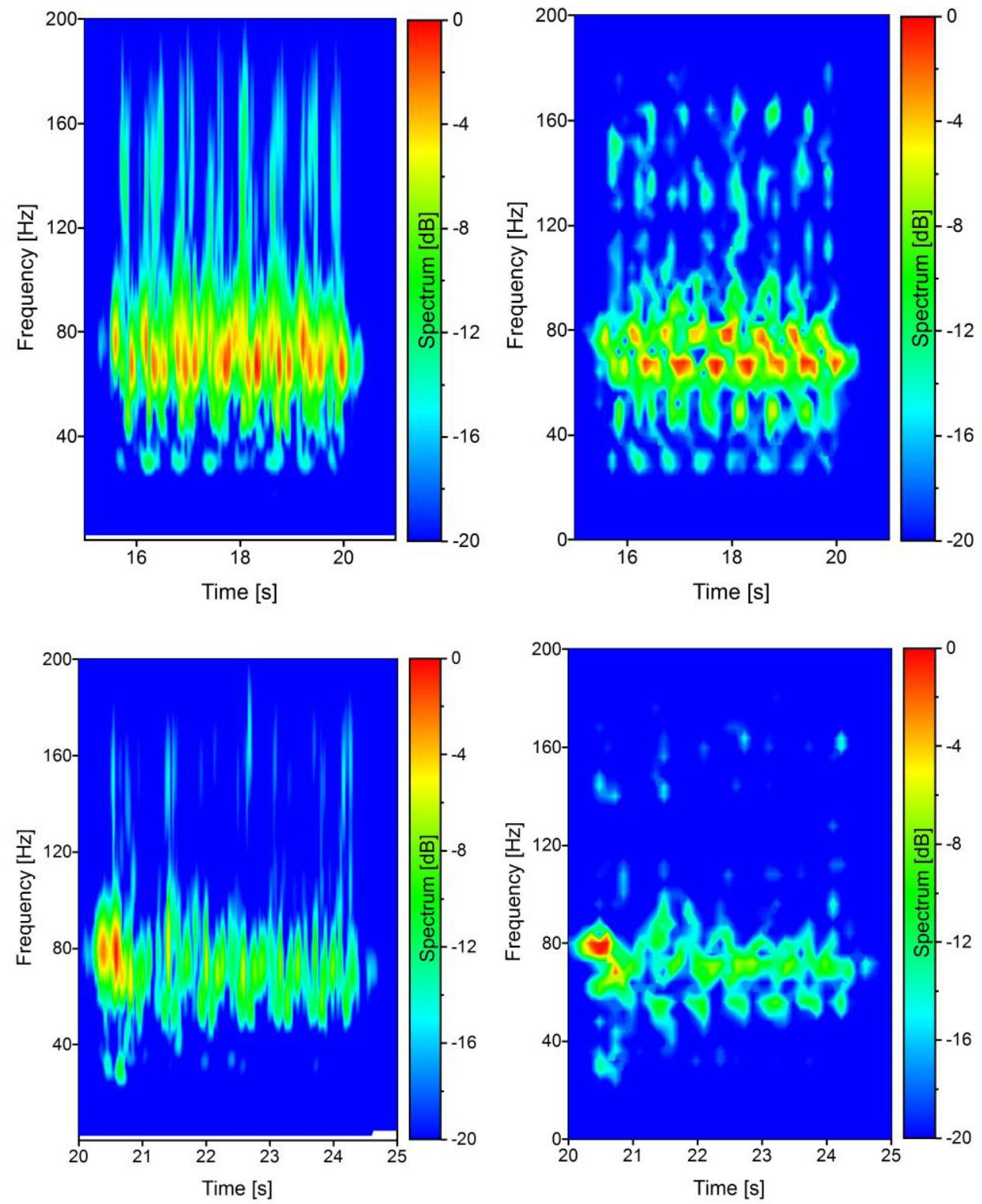

Fig. 6. Sensor P-06z - the value of CWT (the left column) and STFT (the right column) for Pendolino train (the upper row) and the value of CWT (the left column) and STFT (the right column) for InterCity train (the bottom row).

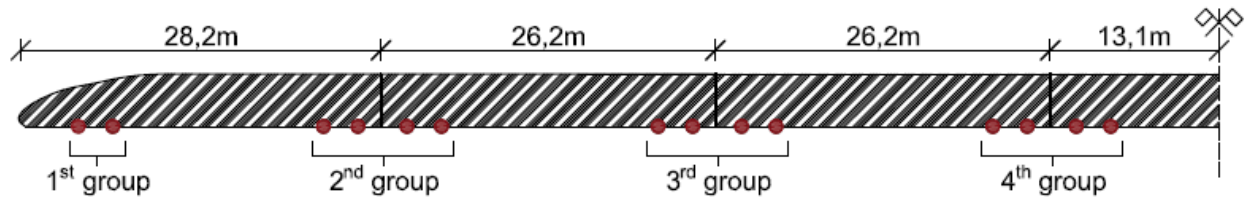

Fig. 7. Pendolino train - schematic arrangement of wheels. 


\section{Conclusions}

Using world literature in the field of mechanical vibration it can be concluded that the vibration excitation of rolling stock is an important problem of the modern world. Therefore, the dynamic studies are necessary for each railway investments. This applies to both the design and construction of new lines and the purchase of new rolling stock.

The results of homologation tests, provides that there is no contraindication for release Pendolino train (Electric Multiple Unit - EMUs 250) for use by the Polish Railway Lines.

This study is a part of broader research aimed at the use of analysis giving an answer in frequency - time domain which should be a supplement for the analysis in the frequency or in the time domain.

As mentioned in [11-13] STFT brings significant limitations in the analysis of nonstationary signals. A large width of the analysis window provides high resolution in the frequency domain, while a low time resolution. A small width of the analysis window ensures high time resolution and a low frequency domain. It causes difficulty in the separation of certain spectral components in the analysis of broadband signals. That CWT's functions are characterized by specific properties - a good location in time (space) and the limited bandwidth in the frequency domain. Therefore, the wavelets are ideal for approximation signals varying in time. Important feature of the wavelet representation is that it includes the information about the signal at different levels of detail.

A time - frequency domain analysis provides more relevant information than classical FFT. Such verification data makes it possible to use vibration damping with special emphasis on the element which induces the largest vibrations. E. g. for vibroisolation design, which reduce vibration induced in the relevant frequency band or for changing the bogies that make the higher amplitudes.

All analysis and calculations were made using FlexPro 7.0 code.

The authors acknowledge the support of research funded by the Ministry of Science and Higher Education - project L-4/349/2016/DS-M.

In situ investigations of vibrations were performed by the Laboratory of Structural Mechanics at Cracow University of Technology. The authors would like to thank the team of the laboratory.

\section{References}

1. D.P.Connolly, G.P. Marecki, G. Kouroussis, I. Thalassinakis, P.K. Woodward, The growth of railway ground vibration problem - A review, Sci Total Environ 568, 1-7, Elsevier (2015)

2. D. P. Connolly, G. Kouroussis, O. Laghrouche, C. Ho and M. Forde, Benchmarking railway vibrations - Track, vehicle, ground and building effects, Constr Build Mater 92, 64-81, Elsevier (2015)

3. L. S. G. Degrande, Free field vibrations during the passage of a Thalys high-speed train at variable speed, J Sound Vib 247 (1), 131-144, Academic Press (2001)

4. X. Sheng, C. J. C. Jones, M. Petyt, Ground vibration generated by a load moving along a railway track, J Sound Vib 228 (1), 129-156 (1999)

5. A. Tesar, J. Melcer, D.Kucharova, Monitoring of small channel slabs in railway track science, Building Research Journal 61, 15 - 24 (2014)

6. T. Tatara, K. Stypuła, Analysis of the results of measurements of ground vibration and some elements of the surface during the test of Pendolino train and other trains on the line CMK in agreed locations in the track No. 1, section Psary - Góra Włodowska, Cracow University of Technology, Cracow (in Polish) (2013) 
7. S. Ervin, I. Djurowić, J.Jiang, Time - frequency feature representation using energy concetration: An overview of resent advances, Digital Signal Procesing 19, 153-183 (2009)

8. T. Basiewicz, Wavelets and approximations, WNT, Warsaw (in Polish) (2004)

9. D. Cantero, M. Ülker-Kaustell, R. Karoumi, Time-frequency analysis of railway bridge response in forced vibration, Mech Syst Signal Pr 76-77, 518-530 (2016)

10. J. Korzeb, Application of wavelet analysis in evaluation of vibrations propagation in transport infrastructure impact zones. Transport XXI century, Department of Transportation Warsaw University of Technology, Białowieża (in Polish) (2010)

11. A. Zacniewski, Comparative analysis of chosen transforms in the context of denoising harmonic signals, Polish Naval Academy in Gdynia, Bulletin of WAT (in Polish) LXIV, 3 (2015)

12. M. Gonera, W. Kiciński, Time-frequency methods of signal analysis, The work of the Institute of Industrial Electronics (in Polish) 149, Warsaw (2004)

13. S. Mallat, A Wavelet Tour of Signal Processing, Academic Press (2008) 